\title{
Case Report \\ Diffuse-Type Tenosynovial Giant Cell Tumor of the Knee with Concurrent Polymicrobial Infection (Klebsiella oxytoca and Group B Streptococcus)
}

\author{
J. Hunter Marshall $\left(\mathbb{D},{ }^{1}\right.$ John G. Skedros $\mathbb{D}^{1},{ }^{1}$ Chris F. Campana $\mathbb{D D}^{2},{ }^{2}$ and Allan M. Seibert $\mathbb{D D}^{3}$ \\ ${ }^{1}$ Utah Orthopaedic Specialists and LDS Hospital, Salt Lake City, UT, USA \\ ${ }^{2}$ Intermountain Healthcare Department of Pathology, Salt Lake City, UT, USA \\ ${ }^{3}$ University of Utah Division of Infectious Diseases and Intermountain Healthcare Division of Infectious Diseases, Salt Lake City, \\ UT, USA
}

Correspondence should be addressed to John G. Skedros; jskedrosmd@uosmd.com

Received 11 February 2021; Revised 21 June 2021; Accepted 6 August 2021; Published 14 August 2021

Academic Editor: George N. Dalekos

Copyright (c) 2021 J. Hunter Marshall et al. This is an open access article distributed under the Creative Commons Attribution License, which permits unrestricted use, distribution, and reproduction in any medium, provided the original work is properly cited.

\begin{abstract}
Tenosynovial giant cell tumors (TGCT) are a rare class of benign proliferative tumors that are classified according to their presentation: localized-type (L-TGCT) or diffuse-type (D-TGCT). TGCT is synonymous with pigmented villonodular synovitis (PVNS). We describe the unique case of a 56-year-old obese male with type 2 diabetes who had polymicrobial septic arthritis of his left knee joint with concurrent D-TGCT in the same knee. While on a vacation, he noticed spontaneous left knee pain and swelling with an acute onset of fever. He was diagnosed with septic arthritis that was attributed to hematogenous spread from a leg laceration. The septic arthritis was treated with arthroscopic lavage and debridement, including simultaneous excision of the D-TGCT lesions, followed by intravenous ceftriaxone. Cultures of the synovial tissue that were obtained during arthroscopy grew Klebsiella oxytoca and beta-hemolytic (group B) Streptococcus agalactiae. We were not able to find another reported case of any joint with (1) a polymicrobial bacterial infection that included Klebsiella oxytoca and (2) concurrent bacterial septic arthritis and TGCT.
\end{abstract}

\section{Introduction}

Tenosynovial giant cell tumor (TGCT) is a general classification of rare, proliferative, usually benign, neoplastic lesion(s) most commonly affecting synovial membranes, tendons, and bursae of joints. TGCT is categorized into two subtypes: (1) localized type (a smooth encapsulated nodule) (L-TGCT) and (2) diffuse type (multiple nodules) (DTGCT). TGCT is pathologically synonymous with pigmented villonodular synovitis (PVNS) and giant-cell tumor of the tendon sheath (GCTTS). Historically, the distinctions between PVNS, TGCT, and GCTTS were predicated on the anatomical location of the lesion(s) as being within the joint capsule, extra-articular regions, or with tendon sheath involvement [1]. TGCT has since become the standard classification for these diseases [2]. For this reason, we use D-TGCT to describe the pathologic diagnosis of our case.

D-TGCT has an incidence of approximately 5 to 8.4 new cases per million person-years $[3,4]$. The most commonly affected joint is the knee, followed by the hip, ankle, shoulder, elbow, and digits in decreasing order [3-6]. The diagnosis of D-TGCT can be delayed for years because these lesions are generally slow growing and early symptoms resemble other conditions such as various forms of erosive arthritis, gout, and soft-tissue injuries. Our literature search (PubMed and Google Scholar) failed to reveal any case where a patient had both D-TGCT and septic arthritis of the same joint. We report a unique case of a type 2 diabetic patient who had D-TGCT with a coexisting polymicrobial bacterial infection of his left knee. The organisms grown in 
tissue culture from his knee included beta-hemolytic (group B) Streptococcus agalactiae (GBS) and Klebsiella oxytoca (KO), the latter being rarely involved in septic arthritis. We report this novel case in the perspective of an overview of the literature that deals with its microbiology, infection etiology, and pathology.

\section{Case Presentation}

Our patient was a seemingly healthy 56 -year-old male $(1.88 \mathrm{~m}$ height and $125 \mathrm{~kg}(\mathrm{BMI}=33.4)$ ) who was admitted to our hospital for acute left knee pain and swelling. An attorney by profession, he had a medical history of non-insulin-dependent (type 2) diabetes mellitus and asthma. He was not taking any medications for his diabetes and infrequently used a corticosteroid inhaler for asthma symptoms. He had no prior history of knee surgery or prior corticosteroid injections into his left knee. Three months prior to being admitted to our hospital, the patient had seen an orthopaedic surgeon for left knee pain. At that time, magnetic resonance imaging (MRI) was performed of his left knee and revealed several multilobulated masses, which can be seen in Figure 1. All of these lesions showed diffuse abnormal enhancements and low signal on T1- and T2-weighted images, consistent with the presence of hemosiderin deposits of TGCT [7-9]. Other MRI findings included mild-to-moderate osteoarthritis of the patellofemoral articulation and posterior-medial femoral condyle and partial tearing of the medial meniscus. Arthroscopic surgery was recommended, but he delayed this in order to accommodate his work schedule.

While out of town, the patient was admitted to a hospital for possible septic arthritis of the left knee. His synovial fluid cultures showed no growth, and a venous blood sample showed leukocytosis $(14.1 \mathrm{~K} / \mu \mathrm{L})$. He was treated with IV antibiotics and instructed to seek continued medical care at his local hospital which was a day's drive away. At our hospital, a second arthrocentesis of his left knee yielded $50 \mathrm{cc}$ of cloudy yellowish fluid. The synovial fluid culture showed no growth, and no crystals were seen under microscopic examination. The knee aspirate cell counts were $<3,000 \mathrm{rbc} /$ $\mu \mathrm{L}$ and $30,426 \mathrm{wbc} / \mu \mathrm{L}$ with $90 \%$ neutrophils, $8 \%$ monocytes, and $2 \%$ lymphocytes. His fasting blood glucose was measured at 122 and $184 \mathrm{mg} / \mathrm{dL}$ (normal range: $65-99 \mathrm{mg} / \mathrm{dL}$ ) over the course of his stay. CRP was $11.0 \mathrm{mg} / \mathrm{dL}$ (normal range: 0.0-1.0 mg/dL). CBC showed persistent leukocytosis with a WBC of $10.7 \mathrm{~K} / \mu \mathrm{L}$ (normal range: $3.6-10.6 \mathrm{~K} / \mu \mathrm{L}$ ). Urinalysis and erythrocyte sedimentation rate (ESR) were negative as were tests for human immunodeficiency virus (HIV), hepatitis C, Gonococcus, and Chlamydia trachomatis.

The on-call orthopaedic surgeon (JGS) performed arthroscopic surgery that day for presumed joint sepsis. The degenerative medial meniscus tear was debrided, and all synovium that could be visualized was removed including the D-TGCT lesions. The synovium was mildly erythematous with diffuse brownish pigmentation, which appeared consistent with recurrent hemarthrosis that contributes to the pigmentation of the synovium in TGCT [10-12]. Three $\sim 2 \mathrm{cc}$ tissue biopsies were taken from the inflamed synovium and villonodular fronds of the larger tumor lesions, which were sent for culture and pathological analysis. The tissues were cultured using chocolate agar, sheep blood agar, and MacConkey agar and subsequently incubated in a thioglycolate broth at $37^{\circ} \mathrm{C}$ in a $\mathrm{CO}_{2}$ atmosphere. Analysis for bacteria species was conducted by MALDI-TOF mass spectrometry. Two of the three specimens tested positive for Klebsiella oxytoca (KO) (Gram-negative bacilli), and all three samples tested positive for beta-hemolytic (group B) Streptococcus agalactiae (GBS) (Gram-positive cocci). Susceptibility tests revealed that both $\mathrm{KO}$ and GBS were susceptible to ceftriaxone. Two grams of ceftriaxone were given IV every 24 hours for four weeks.

Arthroscopic images are shown in Figure 2, and microscopic images of the tumor biopsies are shown in Figure 3. A pathologist consultant (CFC) suspected that the intraarticular lesions seen with MR imaging were TGCT, but because of substantial tissue infarction, he obtained a second opinion from an out-of-state expert on TGCT at a university hospital. The diagnosis of TGCT was then confirmed after examination of additional tissue sections. One year after surgery, the patient reported that he was "fully recovered" and had no evidence of recurrent infection. He is currently scheduled for a follow-up MR scan to provide a postoperative baseline for future comparative analysis should he become symptomatic.

\section{Discussion}

Infections caused by KO are nearly always nonarticular and predominately occur in the nosocomial setting in patients with concurrent medical conditions [13-18]. Similarly, the likelihood of a GBS infection is increased in individuals who are immunocompromised because of underlying conditions such as diabetes [19-21]. When compared to KO joint infections, GBS joint infections are more common [22-27]. Although we could not locate any reported case of a polymicrobial joint infection with KO with any other bacteria species, polymicrobial joint infections are not rare, accounting for about $10 \%$ of nongonococcal cases in adults $[26,28]$.

Of the nearly one-dozen species within the genus Klebsiella, K. pneumoniae is considered the most medically important, causing $75 \%$ to $86 \%$ of clinical Klebsiella infections. The second most commonly cultured species is $\mathrm{KO}$, which accounts for $13 \%$ to $25 \%$ of Klebsiella infections [29-32]. Unlike the occasional occurrence of septic arthritis caused by Klebsiella pneumoniae, reported cases of bacterial septic arthritis caused by $\mathrm{KO}$ are exceedingly rare. In fact, we located only three cases in native (no prior surgery) joints of adults [33].

Given that our patient had no recent hospitalization or invasive medical care, the most likely source of bacterial inoculation was from his antecedent leg laceration from striking it directly on a metal trail hitch. Because normal human skin does not provide good growth conditions for Klebsiella species, they are regarded simply as transient members of the skin flora $[34,35]$. In contrast, GBS is known to colonize normal skin flora [36]. However, Klebsiella and Streptococcus species can exist for up to several weeks on 


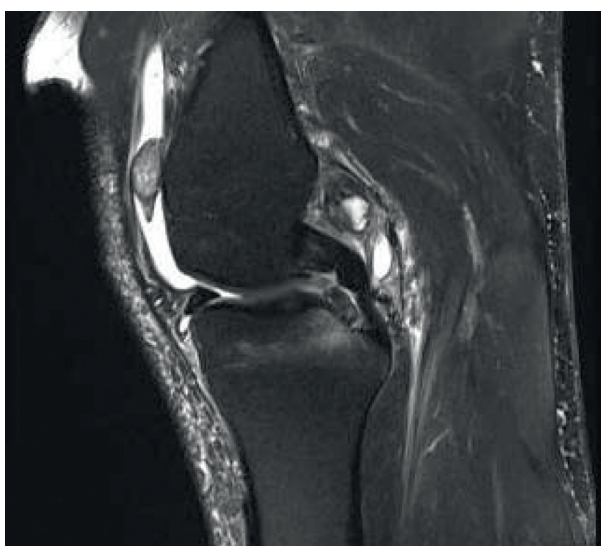

(a)

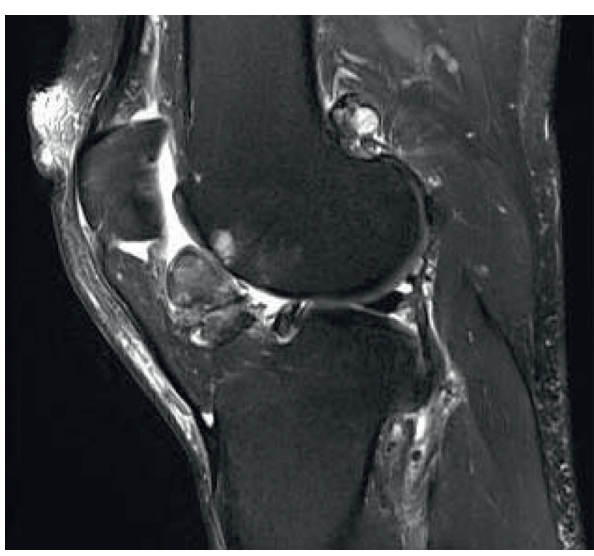

(b)

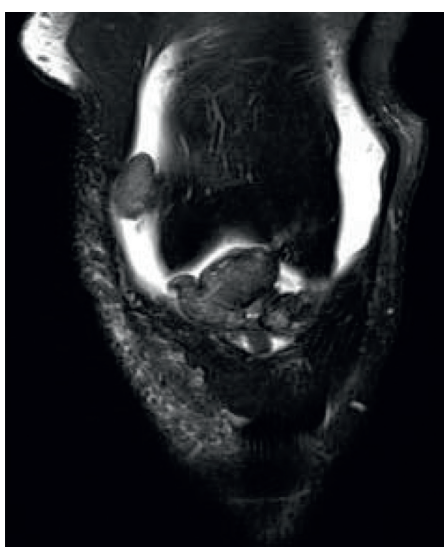

(c)

Figure 1: (a) T2 fat-suppressed (FS) (TR/TE: 5070/76) midsagittal view of the left knee. TGCT nodules can be seen in the patellofemoral location and superior to the posterior cruciate ligament. (b) T2 FS (TR/TE: 5070/76) parasagittal view showing TGCT nodules anterior to the intercondylar notch and posterior-superior to the lateral femoral condyle. (c). T2 FS (TR/TE: 4740/76) coronal view showing the same nodules seen in the patellofemoral region of image (a) and the anterior joint region in image (b). The diffuse low signal of the tumors due to hemosiderin deposition is noted.

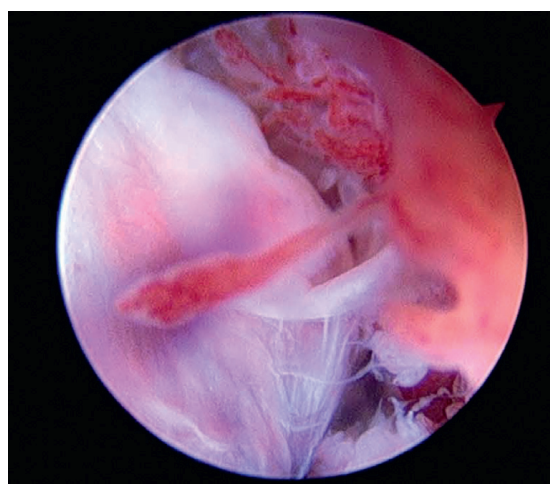

(a)

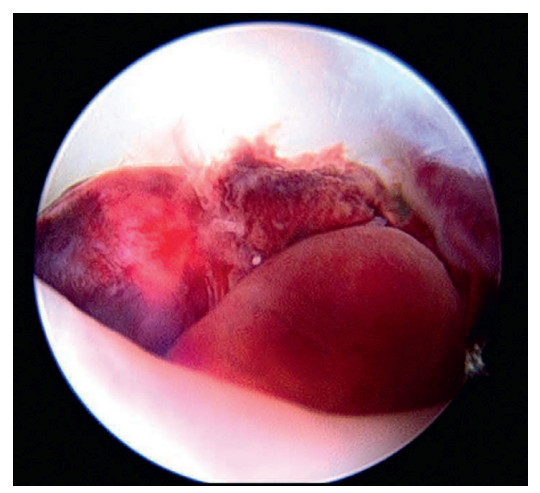

(b)

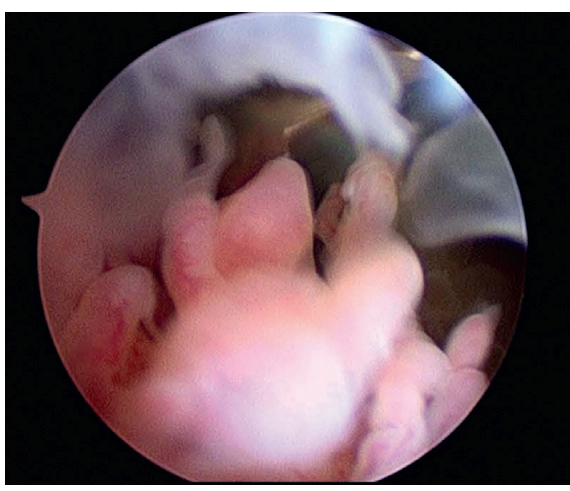

(c)

FIGURE 2: Arthroscopic images showing (a) synovitis that was not believed to have TGCT tissue, (b) infarcted TGCT tissue, and (c) viable TGCT tissue.

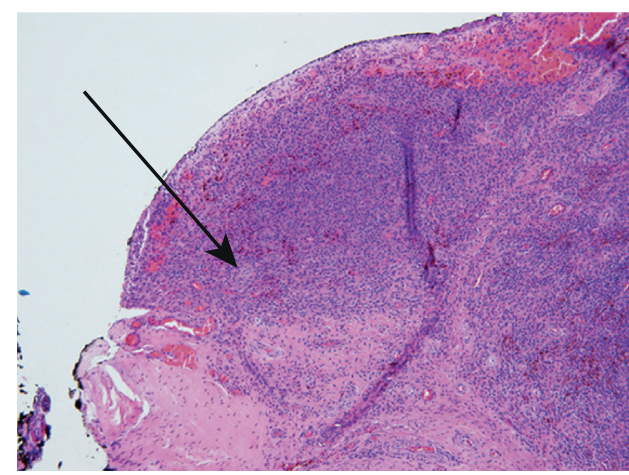

(a)

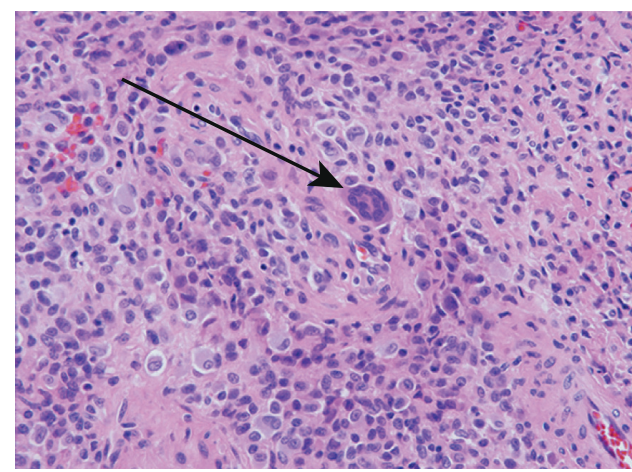

(b)

Figure 3: Continued. 


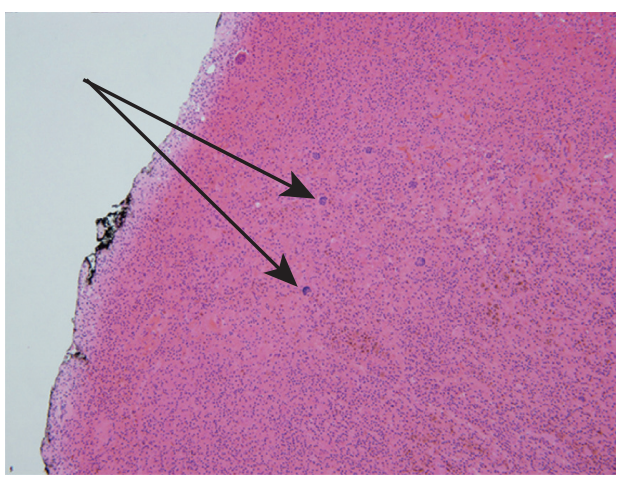

(c)

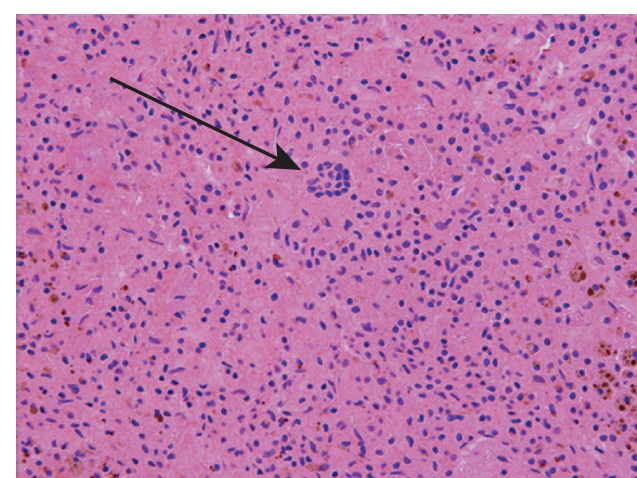

(d)

FIGURE 3: Microscopic images of hematoxylin-eosin-stained sections of tumor tissue. Viable TGCT: (a) 100x image illustrating viable TGCT with scattered giant cells (arrows) and (b) 200x image showing a multinucleated giant cell. Infarcted tissue with scattered giant cells (arrows): (c) $100 \mathrm{x}$ image of completely infarcted tissue with multinucleated giant cells and (d) 200x image of partially infarcted tissue with a multinucleated giant cell.

inanimate objects, including soil and clothing [37, 38]. The introduction of these pathogens via laceration is supported by several clinical studies of patients with $\mathrm{KO}$ or GBS bacteremia $[13-15,21,23,39,40]$.

The most unusual aspect of our unique case was the concurrence of a bacterial infection within the same joint diseased with D-TGCT. Considering how other proliferative inflammatory diseases such as rheumatoid arthritis increase the likelihood of septic arthritis [26, 41, 42], we considered the possibility that the presence of D-TGCT might influence the risk of hematogenous seeding. While synovial membranes have rich vascularity without a limiting basement membrane [26] and TGCT increases production of extracellular matrix proteins (e.g., fibronectin-, fibrogen-, and laminin-binding proteins) which provide an environment for bacterial adhesion, the connection between TGCT and septic arthritis of this case seems incidental considering there have not been any reported cases of TGCT and septic arthritis. However, while these factors may not inherently increase the risk of septic arthritis, the local environment was such that provided much needed factors for attachment/ adhesion, colonization, and persistence for both GBS and KO.

In a comprehensive review of epidemiology, taxonomy, and pathogenicity factors of Klebsiella species, [35] discuss how the growth of bacteria in host tissue is limited not only by the host defense mechanisms but also by the supply of available iron. Iron is essential for bacterial growth, and the supply of free iron available to bacteria in the host milieu is extremely low in most cases. Large deposits of iron can occur in the synovium parenchyma of patients with TGCT as the result of repeated bleeding and subsequent hemoglobin degradation. The hemosiderin-laden parenchyma that is characteristic of TGCT is in large part the result of recurrent hemarthrosis and gives TGCT its distinct MRI characteristics [7, 10, 11, 43]. KO, like K. pneumoniae, can promote growth and biofilm formation and enhance virulence by chelating iron $[44,45]$ that is readily available in joints burdened by TGCT.
MRI analysis is considered the most useful presurgical diagnostic modality of TGCT $[7,8,46]$. In our patient, the severity of D-TGCT based on MRI parameters was classified as moderate diffuse according to the study in [8] (i.e., no musculature, tendon, or ligament was involved, and the lesion was confined to the articular capsule of the knee). Based on these criteria, our patient is estimated to have $59 \%$ likelihood to be recurrence free 4 years postoperatively [8]. Because there was likely residual synovium posterior to the femoral condyles after arthroscopy, we plan to monitor our patient for recurrence.

\section{Conclusions}

We report the unique case of a patient with polymicrobial bacterial infection and D-TGCT of the same knee. One of the bacteria species is common (group B Streptococcus) in joint sepsis, and the other, Klebsiella oxytoca, is extremely uncommon. Characteristics of the synovial membrane and the presence of increased production of fibronectin and other extracellular binding proteins and free iron associated with D-TGCT likely provided an environment that provided a good host for bacterial colonization of his knee. Intravenous antibiotics and arthroscopic debridement effectively treated the infection. During the same arthroscopic surgery, the D-TGCT tissues were excised. Because of the high risk of recurrence, we instructed our patient to follow-up if the knee becomes symptomatic.

\section{Ethical Approval}

Each author certifies that his institution has approved the reporting of this case and that all investigations were conducted in conformity with ethical principles of research.

\section{Consent}

Informed consent for participation in the study was obtained. 


\section{Conflicts of Interest}

The authors declare no conflicts of interest.

\section{References}

[1] R. C. Martin, D. L. Osborne, M. J. Edwards, W. Wrightson, and K. M. McMasters, "Giant cell tumor of tendon sheath, tenosynovial giant cell tumor, and pigmented villonodular synovitis: defining the presentation, surgical therapy and recurrence," Oncology Reports, vol. 7, pp. 413-419, 2000.

[2] B. P. Rubin, "Tenosynovial giant cell tumor and pigmented villonodular synovitis: a proposal for unification of these clinically distinct but histologically and genetically identical lesions," Skeletal Radiology, vol. 36, no. 4, pp. 267-268, 2007.

[3] V. Ehrenstein, S. L. Andersen, I. Qazi et al., "Tenosynovial giant cell tumor: incidence, prevalence, patient characteristics, and recurrence. a registry-based cohort study in Denmark," Journal of Rheumatology, vol. 44, no. 10, pp. 1476-1483, 2017.

[4] M. J. L. Mastboom, F. G. M. Verspoor, A. J. Verschoor et al., "Higher incidence rates than previously known in tenosynovial giant cell tumors," Acta Orthopaedica, vol. 88, no. 6, pp. 688-694, 2017.

[5] W. K. Tyler, A. F. Vidal, R. J. Williams, and J. H. Healey, "Pigmented villonodular synovitis," Journal of the American Academy of Orthopaedic Surgeons, vol. 14, no. 6, pp. 376-385, 2006.

[6] F. G. M. Verspoor, A. A. G. Zee, G. Hannink, I. C. M. van der Geest, R. P. H. Veth, and H. W. B. Schreuder, "Long-term follow-up results of primary and recurrent pigmented villonodular synovitis," Rheumatology, vol. 53, no. 11, pp. 2063-2070, 2014.

[7] X. G. Cheng, Y. H. You, W. Liu, T. Zhao, and H. Qu, "MRI features of pigmented villonodular synovitis (PVNS)," Clinical Rheumatology, vol. 23, no. 1, pp. 31-34, 2004.

[8] M. J. L. Mastboom, F. G. M. Verspoor, D. F. Hanff et al., "Severity classification of tenosynovial giant cell tumours on MR imaging," Surgical Oncology, vol. 27, no. 3, pp. 544-550, 2018.

[9] B. O’Sullivan, B. Cummings, C. Catton et al., "Outcome following radiation treatment for high-risk pigmented villonodular synovitis," International Journal of Radiation Oncology, Biology, Physics, vol. 32, no. 3, pp. 777-786, 1995.

[10] C. Fecek and K. R. Carter, "Pigmented villonodular synovitis," in StatPearlsStatPearls Publishing, Treasure Island, Florida, USA, 2020.

[11] F. J. Frassica, M. A. Bhimani, E. F. McCarthy, and J. Wenz, "Pigmented villonodular synovitis of the hip and knee," American Family Physician, vol. 60, pp. 1404-1415, 1999.

[12] S. Ottaviani, X. Ayral, M. Dougados, and L. Gossec, "Pigmented villonodular synovitis: a retrospective single-center study of 122 cases and review of the literature," Seminars in Arthritis and Rheumatism, vol. 40, no. 6, pp. 539-546, 2011.

[13] B. N. Kim, J. Ryu, Y. S. Kim, and J. H. Woo, "Retrospective analysis of clinical and microbiological aspects of Klebsiella oxytoca bacteremia over a 10-year period," European Journal of Clinical Microbiology \& Infectious Diseases, vol. 21, pp. 419-426, 2002.

[14] J. A. Korvick, C. S. Bryan, B. Farber et al., "Prospective observational study of Klebsiella bacteremia in 230 patients: outcome for antibiotic combinations versus monotherapy," Antimicrobial Agents and Chemotherapy, vol. 36, no. 12, pp. 2639-2644, 1992.

[15] R. D. Lin, P. R. Hsueh, S. C. Chang, Y. C. Chen, W. C. Hsieh, and K. T. Luh, "Bacteremia due to Klebsiella oxytoca: clinical features of patients and antimicrobial susceptibilities of the isolates," Clinical Infectious Diseases, vol. 24, no. 6, pp. 1217-1222, 1997.

[16] D. G. Maki, "Nosocomial bacteremia. an epidemiologic overview," The American Journal of Medicine, vol. 70, no. 3, pp. 719-732, 1981.

[17] P. Muñoz, A. Llancaqueo, M. Rodríguez-Créixems, T. Peláez, L. Martin, and E. Bouza, "Group B streptococcus bacteremia in nonpregnant adults," Archives of Internal Medicine, vol. 157, no. 2, pp. 213-216, 1997.

[18] A. P. Panwalker, G. M. Trager, and P. E. Porembski, "Klebsiella species: antimicrobial susceptibilities, bactericidal kinetics, and in vitro inactivation of beta-lactam agents," Antimicrobial Agents and Chemotherapy, vol. 18, no. 6, pp. 877-881, 1980.

[19] C. R. Phares, R. Lynfield, M. M. Farley et al., "Epidemiology of invasive group B streptococcal disease in the United States, 1999-2005," Journal of the American Medical Association, vol. 299, no. 17, pp. 2056-2065, 2008.

[20] P. Sendi, B. Christensson, I. Uçkay et al., "Group B streptococcus in prosthetic hip and knee joint-associated infections," Journal of Hospital Infection, vol. 79, no. 1, pp. 64-69, 2011.

[21] T. H. Skoff, M. M. Farley, S. Petit et al., "Increasing burden of invasive group B streptococcal disease in nonpregnant adults, 1990-2007," Clinical Infectious Diseases, vol. 49, no. 1, pp. 85-92, 2009.

[22] J.-J. Dubost, M. Soubrier, C. De Champs, J.-M. Ristori, and B. Sauvezie, "Streptococcal septic arthritis in adults. a study of 55 cases with a literature review," Joint Bone Spine, vol. 71, no. 4, pp. 303-311, 2004.

[23] H. Lotz, C. Strahm, V. Zdravkovic, B. Jost, and W. C. Albrich, "Septic arthritis due to streptococci and enterococci in native joints: a 13 year retrospective study," Infection, vol. 47, no. 5, pp. 761-770, 2019.

[24] W. Louthrenoo, N. Kasitanon, S. Wangkaew, S. Hongsongkiat, W. Sukitawut, and R. Wichainun, "Streptococcus agalactiae: an emerging cause of septic arthritis," JCR Journal of Clinical Rheumatology, vol. 20, no. 2, pp. 74-78, 2014.

[25] R. Ruksasakul, P. Narongroeknawin, P. Assavatanabodee, and S. Chaiamnuay, "Group B streptococcus is the most common pathogen for septic arthritis with unique clinical characteristics: data from 12 years retrospective cohort study," $B M C$ Rheumatology, vol. 3, no. 1, p. 38, 2019.

[26] M. E. Shirtliff and J. T. Mader, "Acute septic arthritis," Clinical Microbiology Reviews, vol. 15, no. 4, pp. 527-544, 2002.

[27] V. Wang, J. Tan, L. Pay et al., "A comparison of Streptococcus agalactiae septic arthritis and non-Streptococcus agalactiae septic arthritis," Singapore Medical Journal, vol. 59, no. 10, pp. 528-533, 2018.

[28] L. Singh, M. P. Cariappa, and M. Kaur, "Klebsiella oxytoca: an emerging pathogen?" Medical Journal Armed Forces India, vol. 72, pp. S59-S61, 2016.

[29] D. O. Acheampong and L. K. Boamponsem, "Occurrence and species distribution of Klebsiella isolates: a case study at Komfo Anokye teaching hosptial (Kath) in Ghana," Advances in Applied Science Research, vol. 2, pp. 187-193, 2011.

[30] C. A. Broberg, M. Palacios, and V. L. Miller, "Klebsiella: a long way to go towards understanding this enigmatic jet-setter," F1000prime reports, vol. 6, p. 64, 2014.

[31] D. S. Hansen, H. M. Aucken, T. Abiola, and R. Podschun, "Recommended test panel for differentiation of Klebsiella species on the basis of a trilateral interlaboratory evaluation of 
18 biochemical tests," Journal of Clinical Microbiology, vol. 42, no. 8, pp. 3665-3669, 2004.

[32] D. S. Hansen, A. Gottschau, and H. J. Kolmos, "Epidemiology of Klebsiella bacteraemia: a case control study using Escherichia coli bacteraemia as control," Journal of Hospital Infection, vol. 38, no. 2, pp. 119-132, 1998.

[33] H. M. Markusse and R. J. Timmerman, "Infectious arthritis caused by Klebsiella. a report of two cases," Clinical Rheumatology, vol. 8, no. 4, pp. 517-521, 1989.

[34] W. E. Kloos and M. S. Musselwhite, "Distribution and persistence of Staphylococcus and Micrococcus species and other aerobic bacteria on human skin," Applied Microbiology, vol. 30, no. 3, pp. 381-395, 1975.

[35] R. Podschun and U. Ullmann, "Klebsiella spp. as nosocomial pathogens: epidemiology, taxonomy, typing methods, and pathogenicity factors," Clinical Microbiology Reviews, vol. 11, no. 4, pp. 589-603, 1998.

[36] N. van der Mee-Marquet, L. Fourny, L. Arnault et al., "Molecular characterization of human-colonizing Streptococcus agalactiae strains isolated from throat, skin, anal margin, and genital body sites," Journal of Clinical Microbiology, vol. 46, no. 9, pp. 2906-2911, 2008.

[37] A. Kramer, I. Schwebke, and G. Kampf, "How long do nosocomial pathogens persist on inanimate surfaces? a systematic review," BMC Infectious Diseases, vol. 6, no. 1, p. 130, 2006.

[38] R. N. Zadoks, H. M. Griffiths, M. A. Munoz et al., "Sources of Klebsiella and Raoultella species on dairy farms: be careful where you walk," Journal of Dairy Science, vol. 94, no. 2, pp. 1045-1051, 2011.

[39] S. Madi, S. Natarajan, S. Murali, V. Pandey, and K. Acharya, "A 10 year clinical, laboratory and arthroscopic data analysis of bacterial septic arthritis of adult native knee: a hospitalbased study," Journal of Arthroscopy and Joint Surgery, vol. 7, pp. 210-223, 2020.

[40] J. M. Nolla, C. Gómez-Vaquero, X. Corbella et al., "Group B streptococcus (Streptococcus agalactiae) pyogenic arthritis in nonpregnant adults," Medicine, vol. 82, no. 2, pp. 119-128, 2003.

[41] A. Al-Ahaideb, "Septic arthritis in patients with rheumatoid arthritis," Journal of Orthopaedic Surgery and Research, vol. 3, no. 1, p. 33, 2008.

[42] I. Berger, H. Weckauf, B. Helmchen et al., "Rheumatoid arthritis and pigmented villonodular synovitis: comparative analysis of cell polyploidy, cell cycle phases and expression of macrophage and fibroblast markers in proliferating synovial cells," Histopathology, vol. 46, no. 5, pp. 490-497, 2005.

[43] A. B. Goldman and E. F. DiCarlo, "Pigmented villonodular synovitis. diagnosis and differential diagnosis," Radiologic Clinics of North America, vol. 26, pp. 1327-1347, 1988.

[44] F. Baldi, A. Minacci, M. Pepi, and A. Scozzafava, "Gel sequestration of heavy metals by Klebsiella oxytoca isolated from iron mat," FEMS Microbiology Ecology, vol. 36, no. 2-3, pp. 169-174, 2001.

[45] T. Chen, G. Dong, S. Zhang et al., "Effects of iron on the growth, biofilm formation and virulence of Klebsiella pneumoniae causing liver abscess," BMC Microbiology, vol. 20, p. 36, 2020.

[46] F. G. Verspoor, I. C. van der Geest, E. Vegt, R. P. Veth, W. T. van der Graaf, and H. B. Schreuder, "Pigmented villonodular synovitis: current concepts about diagnosis and management," Future Oncology, vol. 9, no. 10, pp. 1515-1531, 2013. 